\title{
Water Supply System Performance Improvement in the Town of Pirot Using Water Balance IWA Methodology and Numerical Simulations
}

\author{
Dragan RADIVOJEVIĆ, Borislava BLAGOJEVIĆ, Aleksandra ILIĆ
}

\begin{abstract}
The methods for performance measuring and benchmarking proposed by IWA Water Loss Task Force has been adopted worldwide during the last two decades. This methodology and active water loss management is still poorly applied in Serbian water supply systems. This research presents application of hydraulic modelling to estimate water supply network performance in the town of Pirot in Eastern Serbia and evaluate potential effects of active leakage management for water saving using IWA best practice. In the hydraulic model, diurnal demand multipliers for total and registered consumption and leakage exponent are calibrated for the extended period simulation. Calibrated model is then used for hydraulic analysis to estimate system water loss reduction, improvement of the technical performance indicator values and financial savings for the system subdivided in seven pressure management zones. The system pressure control with ten pressure reduction valves was simulated, for two different scenarios: a) using pressure reducing valves with fixed outlet pressure and b) with pressure sustaining valves to maintain the minimum pressure in the zone reference node. Both the resulting water balance and system technical performance indicators are significantly improved in both simulated pressure management scenarios.
\end{abstract}

Keywords: IWA best practice; pressure management; technical performance indicators; water loss reduction; water supply network

\section{INTRODUCTION}

The level of water losses, both real and apparent, is one of the most important efficiency issues for water supply systems around the world. When it has become obvious that integral approach for water supply system management and benchmarking was of primary interest for water utilities, International Water Association (IWA) Water Loss Task Force (WLTF) recommended Best Practice Water Balance (BPWB) and Technical Performance Indicators (PI) [19]. American Water Work Association (AWWA) produced manual for water supply practices for water audits and loss control programs [4]. Technical PIs recommended by IWA WLTF have been calculated for thousands of water supply systems in the world during the last two decades. Many countries have achieved significant results in water leakage management following IWA Performance Indicators and Best Practices including Denmark, Malta, USA, Austria, and Australia [5].

The first steps in water supply system benchmarking in Serbia have been performed over a decade ago [12]. No further significant advancement in water supply systems performance was achieved in the meantime [13]. The infrastructural condition of water supply systems in Serbia is similar to the ones in developing countries [10].

Hydraulic modelling is an initial and important step to forecast the effects of planned leakage management schemes, before any intervention is done in the system [7]. Calibration of hydraulic model requires determination of water demand multipliers and pressure-leakage relationship in a water supply system $[6,20]$, because pressure management is one of the most convenient and efficient measures for water loss reduction.

In this paper, the town of Pirot water supply system (PWSS) has been used as the case study to check potential for IWA BPWB and PI improvement. This system is considered representative for Serbia, because it has PI values close to the average ones for the data set in Serbian water supply systems [12]. Systematic site measurement and data collection during 2016 is followed by mathematical modelling. The research goal is to design representative hydraulic model as a forecasting tool for assessment of both hydraulic and financial effects of potential water leakage reduction and PI values improvement in PWSS even in case of scarce system data. Calibration of water demand multipliers, pressure-leakage relationship and "Unit Loss" is performed for real conditions in PWWS through original multiple iterative process.

\section{MATERIALS AND METHODS}

\subsection{Methods to Estimate Water Supply System PI Values}

IWA "Best Practice" [2] involves standard approach for Water Balance calculations. The methodology for PI calculation is regularly updated, including long and short term action planning, measuring, equipment installation, permanent data acquisition and creating data bases, leakage monitoring, and water loss reduction. Its consistent application brings a need for organizational and systematic changes [3].

For this research, principal components of the IWA Water Balance are used in its original form: System Input Volume (SIV), Authorized Consumption (AC), NonRevenue Water (NRW), Water Losses (WL), Apparent Losses (AL), Unauthorized Consumption (UC), Metering Inaccuracies and Real Losses (RL).

The basic PI with the greatest range of applicability for RL [3, 10], are "Technical Indicator Real Losses" (TIRL) and "Unavoidable Annual Real Losses" (UARL). The non-dimensional Infrastructure Leakage Index (ILI) evaluates infrastructural state of a single system. It is an indicator of wellness of distribution network management, appropriate for water supply systems benchmarking in different areas and countries that use different measurement units [10]. A system is rated as excellent for low ILI value close to 1 , and as poorly maintained for high ILI value (close to 10 or higher), [9].

Software packages (like Epanet and Aquanet) are standard tools to simulate many different consumption scenarios and water loss (WL) in water supply system. Extended period simulation is used for forecasting a system behaviour and WL value. An appropriate tool to 
simulate WL volume distributed over the water supply network is "Unit Loss" and it presents WL volume per kilometre of the water supply network per 1 bar pressure. Total measured WL volume in the system is used here to calibrate Unit Loss and $N 1$ leakage exponent, both at the design stage and as the first step of investigating or comparing existing networks [17]. Namely, in the equation for the Leakage Rate:

$$
L=C_{d} A \times(2 g P)^{N 1}
$$

where $L$ is leakage, $P$ is pressure, $g$ is gravitational constant, $C_{d} A$ is the effective area and $N 1$ is leakage exponent [8]. The most appropriate general equation for simple analysis and prediction of leak rate change due to pressure change is:

$$
L_{1} / L_{0}=\left(P_{1} / P_{0}\right)^{N 1}
$$

where existing $L_{0}$ corresponds to $P_{0}$ and changed $L_{1}$ to $P_{1}$ in a node of a distribution system. It was proven worldwide both in laboratory and in the field, that exponent $N 1$ depends on percentage of rigid (non-elastic) pipes in the system [16] and has values from 0,5 for leaks with fixed area up to 1,5 for leaks where area varies with pressure.

Water balance in a real water supply system generated by numerical simulations for extended period is used to estimate water supply system performance and technical performance indicators. Numerical simulations in the calibrated model are used to test the effectiveness on system performance and benefits of two management schemes in a real water supply system before their implementation on site.

\subsection{The State of Water Supply Systems in Serbia}

Traditional four system efficiency PI and IWA Best Practice PI have been estimated for 36 water supply systems in Serbia upon data collected during 2004 - 2005 [12]. The estimated average ILI value for the investigated Serbian water supply systems was about 11 (Fig. 1).

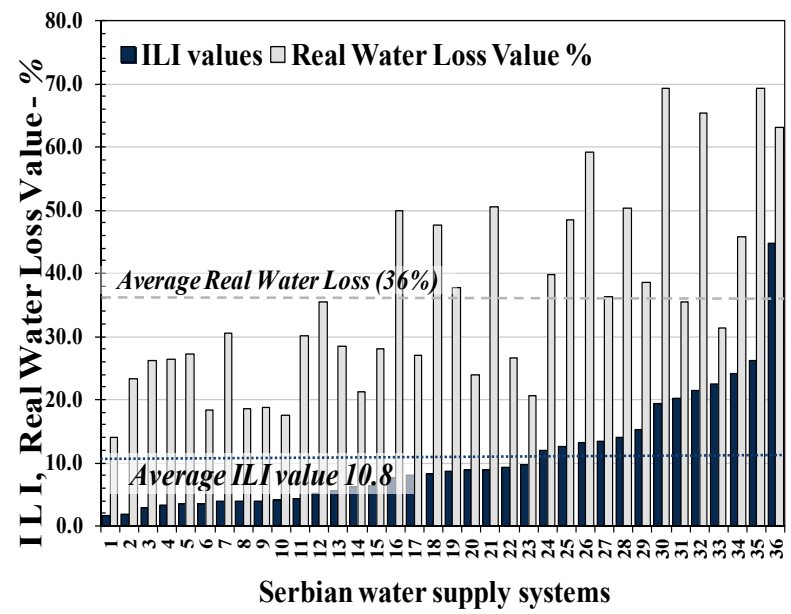

Figure $1 \mathrm{ILI}$ and Water Loss (\%) in 36 water supply systems in Serbia [14]
Average RL, expressed in the "outdated" percentage of SIV was $36 \%$. Recent data from Serbian water supply systems show that the state of supplying networks remained the same [13].

\subsection{Pirot Water Supply System Description}

The town of Pirot is situated in the Eastern part of Serbia (Fig. 2). There are about 46000 consumers supplied by the PWSS (Fig. 3). Two karst water springs are being used for water supply (Kavak and Krupac), while the third spring (Gradište), is occasionally used during summer months. The system is pressurized during the whole year. Two pumping stations are installed in the PWSS: Kavak, on the Kavak spring, and buster pumping station Berilovac on the pipeline from Krupac toward the town central area. Two storage tanks store water for the town: Sarlah $\left(2000 \mathrm{~m}^{3}\right)$, and Pirot $\left(5000 \mathrm{~m}^{3}\right)$.

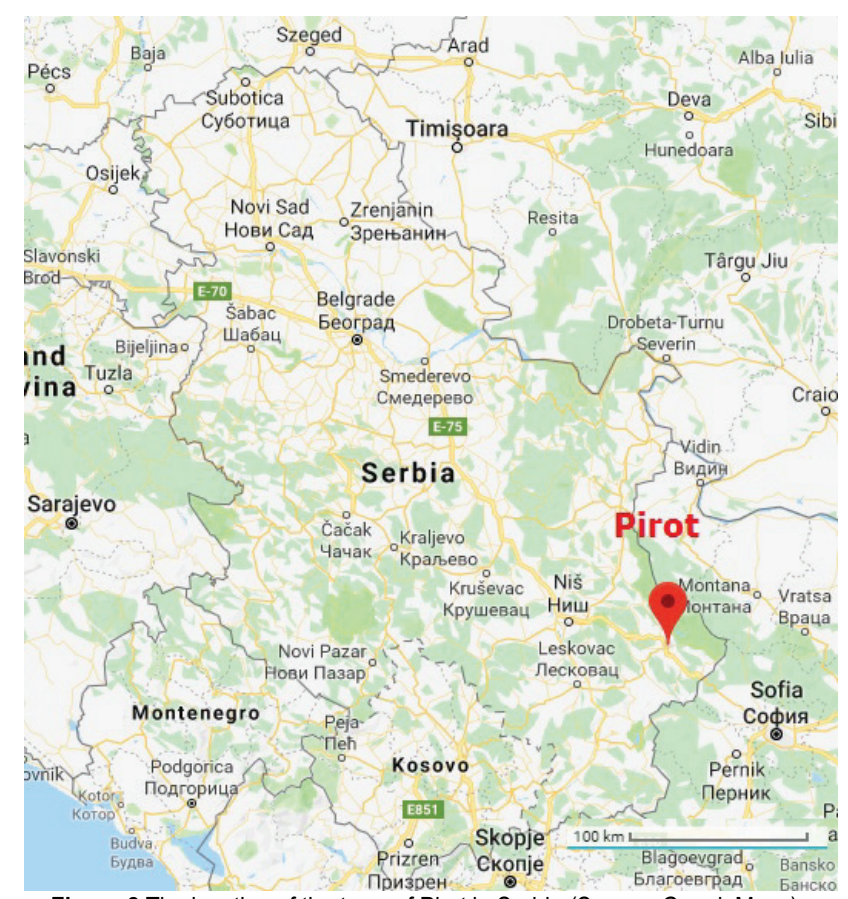

Figure 2 The location of the town of Pirot in Serbia (Source: GoogleMaps)

The water supply network is mostly composed of steel and asbestos cement pipes, many of them over 50 years old. Recently constructed parts are composed of polyethylene and ductile iron pipes. Total length of the water supply network is about $120 \mathrm{~km}$.

\begin{tabular}{|c|c|c|c|c|c|}
\hline \multicolumn{6}{|c|}{ Pipeline length and material in Pirot water supply system } \\
\hline \multirow{4}{*}{ 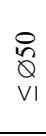 } & Steel \& Iron & 5436 & \multirow{4}{*}{$\begin{array}{l}8 \\
8 \\
1 \\
0 \\
8\end{array}$} & $\mathrm{PE}$ & 17826 \\
\hline & $\mathrm{AC}$ & 9260 & & $\mathrm{AC}$ & 17715 \\
\hline & PVC & 16102 & & Cast Iron & 5000 \\
\hline & Total $/ \mathrm{m}$ & 30798 & & Total $/ \mathrm{m}$ & 17826 \\
\hline \multirow{4}{*}{ 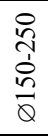 } & LG & 2665 & \multirow{4}{*}{ 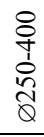 } & Steel & 135 \\
\hline & $\mathrm{AC}$ & 580 & & Cast Iron & 3325 \\
\hline & $\mathrm{PE}$ & 630 & & $\mathrm{AC}$ & 1890 \\
\hline & Total $/ \mathrm{m}$ & 3875 & & Total / m & 5350 \\
\hline \multirow{6}{*}{$\begin{array}{l}8 \\
\text { + } \\
1 \\
o \\
\stackrel{2}{1} \\
Q\end{array}$} & Steel & 135 & \multirow{5}{*}{\begin{tabular}{l}
8 \\
8 \\
1 \\
8 \\
8 \\
\multirow{Q}{1}{}
\end{tabular}} & AC 500 & 7030 \\
\hline & Cast Iron & 3325 & & $\mathrm{AC} 600$ & 8800 \\
\hline & $\mathrm{AC}$ & 1890 & & $\mathrm{AC} 400$ & 2755 \\
\hline & Total / m & 5350 & & Steel & 881 \\
\hline & & & & Total / m & 19466 \\
\hline & & & & length / $\mathrm{m}$ & 120390 \\
\hline
\end{tabular}

Table 1 Pipe material in Pirot water supply system 


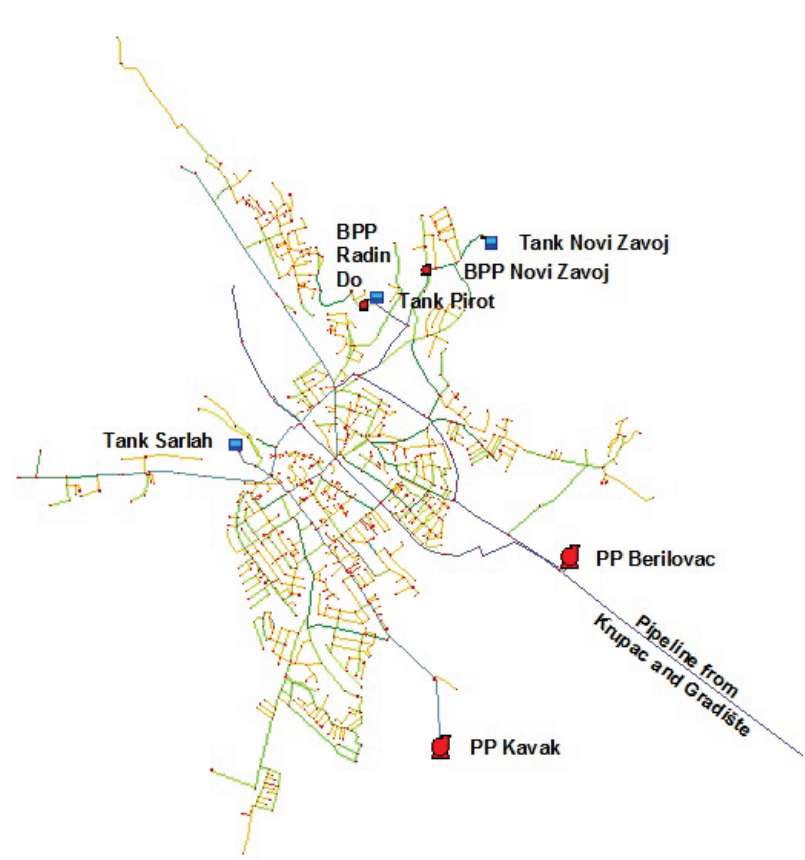

Figure 3The layout of the Pirot Water Supply System

The main and the largest PWSS zone is situated in the central town area, supplying over $90 \%$ of consumers. The central town area is rather flat, with an average elevation of $365 \mathrm{~m}$ a.s.1. The pressure varies in the range 4,5-5,5 bar in the distribution network. Water consumption is metered by volumetric service meters.

The industrial area is gravitationally supplied through the separate pipeline from the Krupac - Gradište springs. This pipeline has a separate measuring system and there is no interaction with the communal water supply system, thus not considered in the paper.

During the year 2005 electromagnetic flow meters have been installed in the pumping stations Kavak and Berilovac and fixed level meters in the storage tanks Sarlah and Pirot. System input discharge and water levels in the tanks have been permanently measured since then. All metering equipment is connected to the operational centre; real time data on water level in the tanks are used by the automatic/operator action for switching pumps on/off or to maintain constant flow in the pumping stations. All discharge and tank level data are being recorded and stored in daily data bases.

System input discharge in PWSS typically varies in the range 120-270 1/s during a day.

\subsection{Water Consumption in Pirot Water Supply System}

Average daily SIV in the residential area, calculated upon data registered on the flow and level meters during the year 2016 are shown in the Tab. 2.

$\mathrm{AC}$ for residential area, public institutions and small business is estimated from the data metered on the service meters. The unmetered AC is estimated to $1 \%$ of the SIV. WL consists of Apparent Losses (Unauthorized Consumption and Metering Inaccuracies) and Real Loss (leakage on transmission and distribution mains, leakage and overflows at storage tanks and leakage on service connections up to the customer meters). Average WL amount is about $44 \%$ in the residential area.
Table 2 Water balance in Pirot water supply system during 2016

\begin{tabular}{|c|c|c|c|c|}
\hline Water Balance & $\begin{array}{c}\text { System } \\
\text { Input }\end{array}$ & Authorized & $\begin{array}{c}\text { Water } \\
\text { Loss }\end{array}$ & $\begin{array}{c}\text { Water } \\
\text { Loss }\end{array}$ \\
\hline Month & $\mathrm{m}^{3} /$ day & $\mathrm{m}^{3} /$ day & $\mathrm{m}^{3} /$ day & $\%$ \\
\hline January & 17219 & 8124 & 8904 & 52 \\
\hline February & 19538 & 10637 & 8874 & 45 \\
\hline March & 17792 & 8886 & 8775 & 49 \\
\hline April & 16930 & 9587 & 7368 & 44 \\
\hline May & 17262 & 10668 & 6739 & 39 \\
\hline June & 16930 & 10213 & 6826 & 40 \\
\hline July & 19865 & 10997 & 8864 & 45 \\
\hline August & 19980 & 10843 & 9105 & 46 \\
\hline September & 19640 & 11875 & 7895 & 40 \\
\hline October & $\mathbf{1 8 9 2 4}$ & $\mathbf{1 0 6 8 4}$ & $\mathbf{8 2 6 4}$ & $\mathbf{4 4}$ \\
\hline November & 19621 & 10344 & 9205 & 47 \\
\hline December & 16283 & 9230 & 7079 & 43 \\
\hline Average & $\mathbf{1 8 3 3 2}$ & $\mathbf{1 0 1 7 4}$ & $\mathbf{8 1 5 8}$ & $\mathbf{4 5}$ \\
\hline
\end{tabular}

\subsection{Pirot WSS - Input Data Preparation, Model Parameter Calibration and Hydraulic Analysis}

Mathematical model of the PWSS is generated in the professional software package AquanetS [17]. All pipes in the network are included, following the PWSS technical documentation and database on pipe material, age and diameter. In the research preparatory stage, asset of site tests was performed using geodesy instruments, 6 pressure data loggers (SEBA), 1 mobile ultrasound flow meter (SEBA) beside the PWSS flow and tank level meters, to check performance and parameters of the main pipelines in the network (joint altitude, pipe diameter and roughness coefficient).

Available data on water consumption were analysed for the year 2016 in order to estimate PWSS water balance and performance. Daily variation in water consumption was estimated from recorded data on system input discharge measured by flowmeters and level change in the storage tanks at 15 min intervals.

Hourly demand multipliers of average daily consumption rate are calculated for every single day during the year 2016 upon recorded water consumption. The multipliers are analysed in the categories: average day, working and weekend day. Then, representative demand multipliers are estimated for each month, as average value in the same hour for all days in the month.

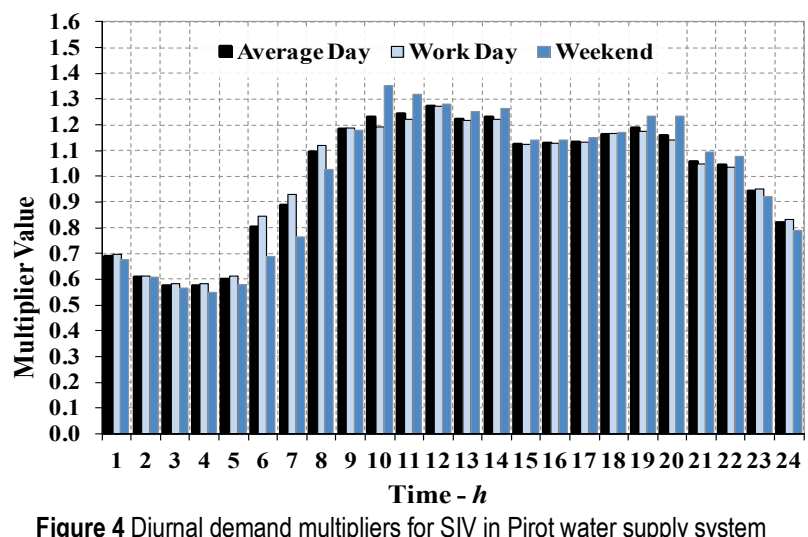

Figure 4 Diurnal demand multipliers for SIV in Pirot water supply system during work and weekend days, year 2016

The values of the generated demand multiplier are rather similar for all three categories, for all months in the study period. Because the most reliable and closest to the average annual data were recorded in October 2016, this 
demand pattern was adopted for further analysis and simulation in the mathematical model (Fig. 4). Therefore, generated demand multipliers are considered representative for the SIV, i.e. for the sum of AC and WL.

For conducting water supply network hydraulic analysis aimed at estimating IWA BP Water Balance, PWSS demand multipliers are calibrated for the Authorized Consumption plus Apparent Loss (Unmetered Consumption and Metering Inaccuracies) and marked as $\mathrm{AC}+$ ). SIV in that way becomes a sum of the $\mathrm{AC}+$ and Real Loss (RL).

The nodal demands in the mathematical model are generated upon geographical position, street and address of service meters. Registered consumption for October 2016 on the service meters is accumulated in the nearest node and enlarged proportionally for the estimated Unmetered Consumption, Apparent Loss and Metering Inaccuracies ( $1 \%$ of SIV each), and the sum of these water balance components is $\mathrm{AC}+$. The purpose of this approach was to separate SIV into AC+ and RL and to test potential of the two leakage management schemes (scenarios) to reduce RL volume, while Apparent and Metering Losses should be reduced using more precise metering equipment i.e. service and flow meters.

Hydraulic analyses on the mathematical model were done for the extended time simulation, with the discrete calculation step of $15 \mathrm{~min}$.

Demand multipliers for AC+ and parameters for Real Loss (RL) are simultaneously calibrated in the iterative process on the mathematical model. The initial demand multipliers for the AC+ are assumed the same as hourly demand multipliers for the total SIV for October 2016.

$\mathrm{RL}$ is considered dependent on water pressure in the supply network. RL is modelled by using Unit Loss and distributed spatially in the water network nodes, depending on the relevant pressure in the node. Initial Unit Loss value was $17,55 \mathrm{~m}^{3} / \mathrm{km} /$ day per 1 bar pressure, matching the volume of average daily RL. During the calibration process (Fig. 5), pressure driven water losses concentrated in nodes are calculated by exponential Eq. (2) using calculated pressures and predefined exponent $N 1$ in corresponding nodes. The software [17] allows $N 1$ value setting in each network node.

After RL daily variation is calculated in the mathematical model for the initial demand patterns matching daily RL volume, it is subtracted from the total SIV to calculate the AC+ for every hour during a day. In that way, new $\mathrm{AC}+$ demand patterns are generated, and the next iteration starts with new $\mathrm{AC}+$ demand patterns to calculate daily pressure variation again. $\mathrm{RL}$ is dependent on pressure value, so Unit Loss value has to be corrected for the next iteration. A couple of iterations is needed for $\mathrm{AC}+$ demand patterns and Unit Loss values to converge for the predefined $N 1$ value.

During the model calibration process, predefined value for exponent $N 1$ is varied in the range 0,8 to 1,15 with an increment of 0,01 . This range is recommended in the case of unknown pipe material and leakage level [16]. For each $N 1$ value, corresponding Unit Loss value is determined, and function $F(N 1)$, which is difference between assumed and calculated RL volume.

$N 1, \mathrm{AC}+$ demand patterns and Unit Loss value which gives minimum $F(N 1)$ value are considered representative values at the end of calibration process.

Through this convergent calibration process for PWWS, mathematical model gave the best fit for the $N 1$ value of 0,95 and Unit Loss $16,88 \mathrm{~m}^{3} / \mathrm{km} /$ day per 1 bar pressure, matching multiple validation criteria: recorded and calculated values of daily RL volume, SIV, recorded and calculated tanks water level variations.

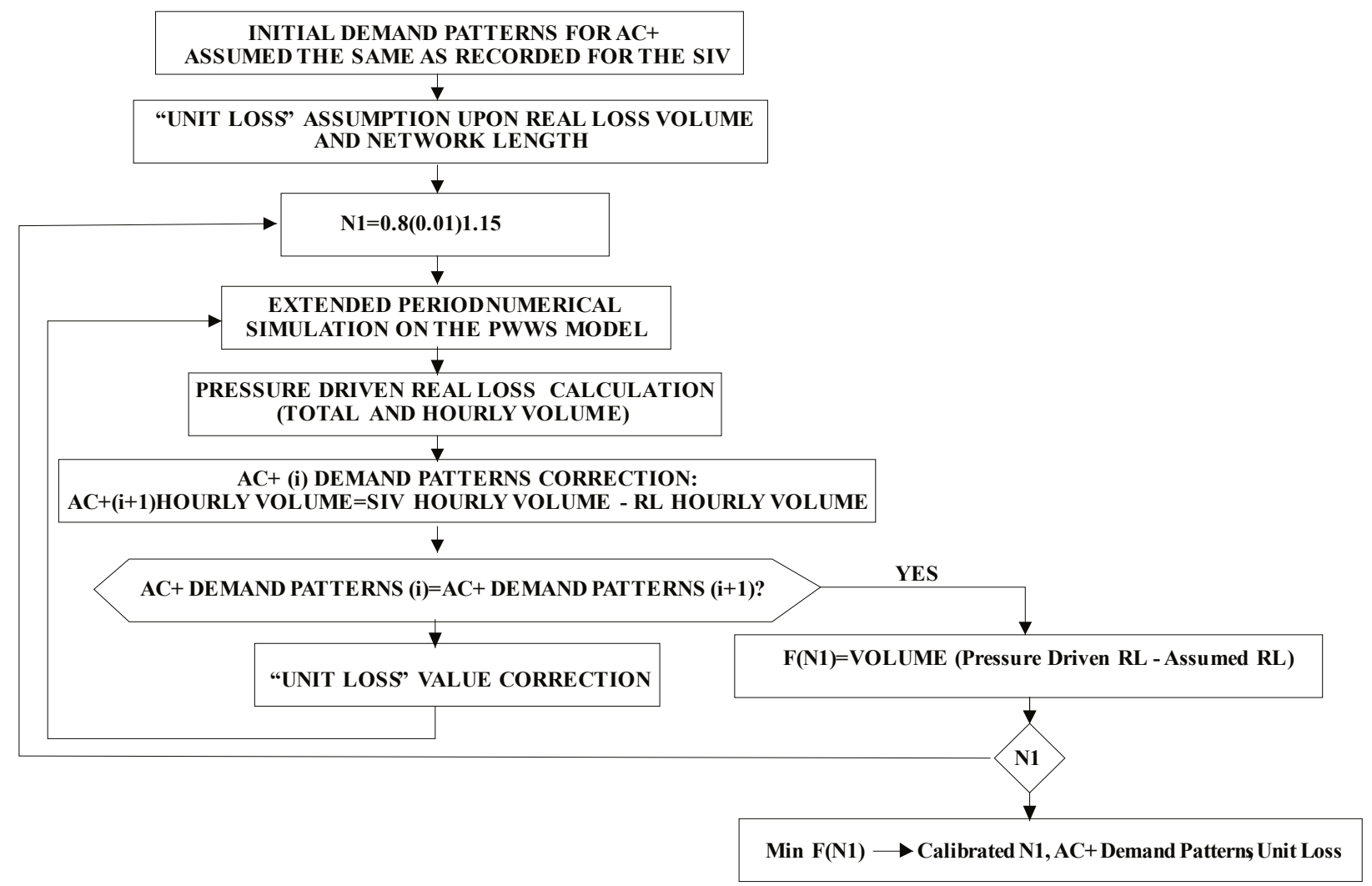

Figure 5 Numerical model parameters calibration - flowchart 
As the result of the described calibration process, estimated $\mathrm{AC}+$ daily demand multipliers are shown in Fig. 6, together with SIV daily demand multipliers.

There is a higher variation of the $\mathrm{AC}+$ during the day compared to variation of the SIV. In the former case, maximum to minimum value is 8 times higher, in the latter case this ratio is 2 , indicating high leakage levels pronounced during the night hours. On the other side, RL value has small daily variation: it is slightly higher during a night.

Using these AC+ daily demand multipliers, N1 exponent and Unit Loss value in the mathematical model of PWSS, water balance components at the annual level were obtained (Tab. 3). The WB components: SIV, AC+, and RL are equal to the ones measured for the year 2016. Therefore, the model was verified and could be used to simulate system response at the present and similar system conditions. IWA BMP WB in PWSS, based on the metered data and numerical simulations is shown in Tab. 3 .

WL (45\%) consists of the AL (estimated 2\%) and RL $(43 \%)$. Leakage and overflows at storage tanks are estimated to $1 \%$ of SIV. The rest of RL is divided in the categories Leakage on transmission and distribution mains (19\%) and Leakage on service connections (23\%). Estimations are based on pipe lengths on mains and service connections.

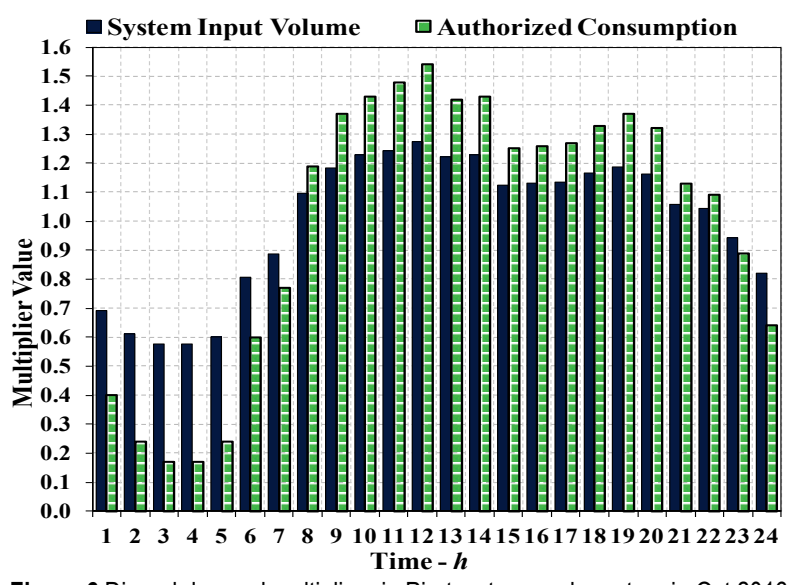

Figure 6 Diurnal demand multipliers in Pirot water supply system in Oct 2016

Table 3 IWA Best Management Practice Water Balance in Pirot water supply system

\begin{tabular}{|c|c|c|c|c|}
\hline \multirow{6}{*}{$\begin{array}{c}\text { System } \\
\text { Input } \\
\text { Volume } \\
\text { (corrected } \\
\text { for known } \\
\text { errors) } \\
6687717 \mathrm{~m}^{3} \\
(100 \%)\end{array}$} & \multirow{2}{*}{$\begin{array}{c}\text { Authorized } \\
\text { Consumption } \\
3710793 \mathrm{~m}^{3} \\
(55 \%)\end{array}$} & $\begin{array}{c}\text { Billed } \\
\text { Authorized } \\
\text { Consumption } \\
3309530 \mathrm{~m}^{3}(49 \%) \\
\end{array}$ & $\begin{array}{c}\text { Billed Metered Consumption } \\
3309530 \mathrm{~m}^{3}(49 \%) \\
\text { Billed Unmetered Consumption } \\
0\end{array}$ & $\begin{array}{c}\text { Revenue } \\
\text { Water } \\
3309530 \mathrm{~m}^{3} \\
(49 \%)\end{array}$ \\
\hline & & $\begin{array}{l}\text { Unbilled Authorized } \\
\text { Consumption } \\
401263 \mathrm{~m}^{3}(6 \%)\end{array}$ & $\begin{array}{c}\text { Unbilled Metered Consumption } \\
334386 \mathrm{~m}^{3}(5 \%) \\
\text { Unbilled Unmetered Consumption } \\
66877 \mathrm{~m}^{3}(1 \%) \\
\end{array}$ & \multirow{5}{*}{$\begin{array}{c}\text { Non-Revenue } \\
\text { Water } \\
(\mathrm{NRW}) \\
3323737 \mathrm{~m}^{3} \\
(51 \%)\end{array}$} \\
\hline & \multirow{4}{*}{$\begin{array}{c}\text { Water } \\
\text { Losses } \\
2976923 \mathrm{~m}^{3} \\
(45 \%)\end{array}$} & $\begin{array}{c}\text { Apparent } \\
\text { Losses } \\
133754 \mathrm{~m}^{3}(2 \%)\end{array}$ & $\begin{array}{c}\text { Unauthorised Consumption } \\
66877 \mathrm{~m}^{3}(1 \%) \\
\text { Metering Inaccuracies } \\
66877 \mathrm{~m}^{3}(1 \%)\end{array}$ & \\
\hline & & \multirow{3}{*}{$\begin{array}{c}\text { Real } \\
\text { Losses } \\
2843169 \mathrm{~m}^{3} \\
(43 \%)\end{array}$} & $\begin{array}{c}\text { Leakage on Transmission and/or } \\
\text { Distribution Mains } 1247480 \mathrm{~m}^{3}(19 \%)\end{array}$ & \\
\hline & & & $\begin{array}{c}\text { Leakage and Overflows at Utility's } \\
\text { Storage Tanks } 66877 \mathrm{~m}^{3}(1 \%)\end{array}$ & \\
\hline & & & $\begin{array}{c}\text { Leakage on Service Connections up to the point of Customer } \\
\text { metering } 1528812 \mathrm{~m}^{3}(23 \%)\end{array}$ & \\
\hline
\end{tabular}

\subsection{Active Leakage Control Effects in PWSS - Simulation on the Mathematical Model}

One of the most convenient measures to reduce water loss in the water supply system is pressure control. Dividing a system in pressure management zones, with pressure controlled by an optimal number of pressure control valves [11], improves system operation results: lowers water loss rate, reduces burst number, prolongs pipe and device life. Reduced pressure in water supply system management zones should be verified by numerical models $[15,16]$ before introducing control devices on the site. For this research, PWSS mathematical model is reconfigured in 7 pressure management zones (industrial zone is not analyzed as it has own independent system). Conceptual design for introducing pressure control zones is shown in Fig. 7.

To estimate potential for water saving and impact of pressure reduction on the system PI, results from the hydraulic simulations are used.

In the first case, pressure is controlled by 10 pressure reducing valves (PRV), installed with fixed outlet pressure values which stop pressure in the downstream reference node from rising above the given limit during the whole day. The adopted criterion for the given pressure limit is that pressure in any network node in the pressure management zone has to be higher than $20 \mathrm{~m}$ during all 24 hrs to provide normal network functionality.

In the second case, pressure is controlled by 10 pressure sustaining valves (PSV) to maintain the minimum pressure of $20 \mathrm{~m}$ in the reference pressure management zone node during $24 \mathrm{hrs}$, to provide normal network functionality. The second scheme allows more active pressure control, especially during the night hours.

\section{RESULTS AND DISCUSSION}

Numerical simulations on the PWWS "as is" model have shown that RL has very small daily variation, 87-97 1/s, while $\mathrm{AC}+$ has significant variation, 24-185 1/s. The lowest $\mathrm{AC}+$ is between 2 and 3 a.m., matching the SIV lowest value.

Assuming $\mathrm{AC}+$ remains the same in the pressure reduction work scheme, results from simulated two leakage management schemes are compared to the current management scheme. RL with simulated reduced pressure control in the first case (10 PRV), varies in the range 69-86 1/s during a day. 
Reduction in RL volume estimated by numerical simulations is about $16 \%$, and reduction of the total SIV is about $7 \%$. This leakage management scheme could potentially save $457865 \mathrm{~m}^{3}$ of potable water per year, or $228932 €$ for water supply utility, taking unit water production cost of $0,5 € / \mathrm{m}^{3}$ (Tab. 4).

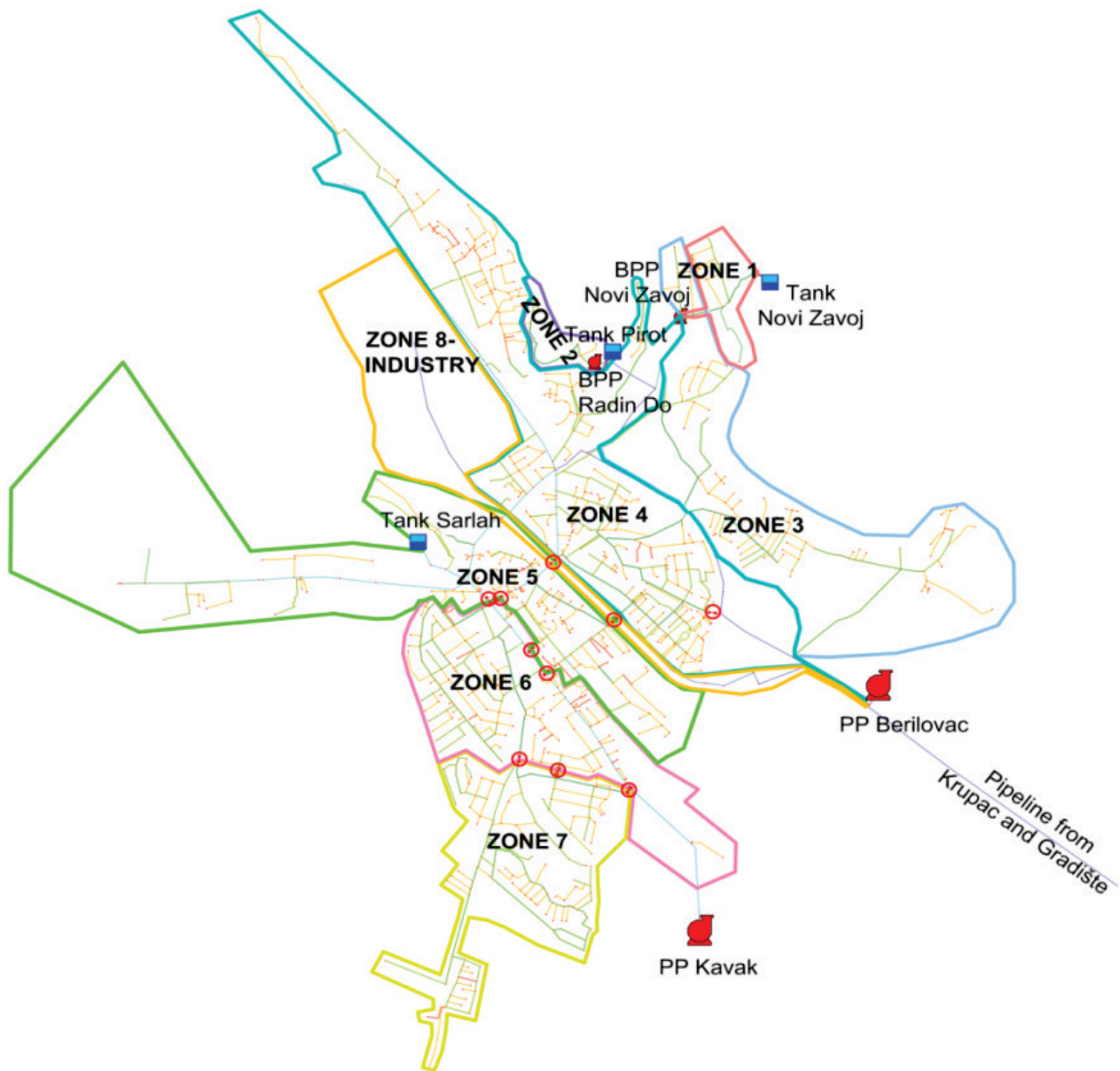

Figure 7 Pirot water supply system reshaped - 7 pressure management zones with 10 pressure regulating valves and independently supplied industrial zone No 8

Table 4 Water consumption and Real Water Loss in Pirot water supply system during a day

\begin{tabular}{|c|c|c|c|c|c|c|c|c|c|}
\hline & \multicolumn{3}{|c|}{ Without pressure management } & \multicolumn{3}{|c|}{ PRV-constant outlet Pressure } & \multicolumn{3}{|c|}{ PSV Pressure Sustaining Value } \\
\hline & $\mathrm{AC}+$ & RL & SIV & $\mathrm{RL}$ & SIV & Water Save & $\mathrm{RL}$ & SIV & Water Save \\
\hline Hour & $1 / \mathrm{s}$ & $1 / \mathrm{s}$ & $1 / \mathrm{s}$ & $1 / \mathrm{s}$ & $1 / \mathrm{s}$ & $1 / \mathrm{s}$ & Loss & $1 / \mathrm{s}$ & $1 / \mathrm{s}$ \\
\hline 0 & 50 & 95 & 146 & 84 & 134 & 11 & 64 & 114 & 31 \\
\hline 1 & 32 & 95 & 127 & 86 & 117 & 10 & 62 & 94 & 33 \\
\hline 2 & 24 & 96 & 120 & 86 & 111 & 9 & 63 & 87 & 33 \\
\hline 3 & 25 & 97 & 122 & 86 & 111 & 11 & 61 & 86 & 36 \\
\hline 4 & 34 & 96 & 130 & 82 & 116 & 14 & 63 & 97 & 33 \\
\hline 5 & 77 & 95 & 172 & 79 & 156 & 16 & 65 & 142 & 30 \\
\hline 6 & 100 & 94 & 194 & 74 & 174 & 20 & 69 & 169 & 25 \\
\hline 7 & 147 & 91 & 238 & 72 & 219 & 19 & 73 & 220 & 18 \\
\hline 8 & 166 & 89 & 255 & 71 & 237 & 18 & 75 & 241 & 14 \\
\hline 9 & 172 & 88 & 261 & 70 & 243 & 18 & 77 & 249 & 11 \\
\hline 10 & 177 & 88 & 264 & 69 & 246 & 18 & 77 & 254 & 11 \\
\hline 11 & 185 & 87 & 272 & 70 & 255 & 17 & 78 & 263 & 9 \\
\hline 12 & 174 & 88 & 261 & 70 & 244 & 17 & 78 & 252 & 10 \\
\hline 13 & 174 & 87 & 260 & 73 & 246 & 14 & 78 & 252 & 9 \\
\hline 14 & 151 & 88 & 239 & 73 & 224 & 15 & 73 & 224 & 15 \\
\hline 15 & 149 & 88 & 237 & 72 & 221 & 16 & 73 & 222 & 15 \\
\hline 16 & 152 & 88 & 240 & 71 & 224 & 17 & 73 & 225 & 15 \\
\hline 17 & 159 & 88 & 246 & 71 & 230 & 17 & 75 & 234 & 13 \\
\hline 18 & 164 & 87 & 251 & 71 & 235 & 16 & 75 & 239 & 12 \\
\hline 19 & 161 & 87 & 248 & 74 & 235 & 13 & 75 & 236 & 12 \\
\hline 20 & 138 & 87 & 225 & 75 & 212 & 12 & 69 & 207 & 18 \\
\hline 21 & 129 & 88 & 217 & 75 & 204 & 13 & 68 & 197 & 20 \\
\hline 22 & 107 & 89 & 197 & 81 & 188 & 8 & 65 & 172 & 24 \\
\hline 23 & 78 & 91 & 169 & 81 & 159 & 10 & 64 & 142 & 27 \\
\hline Average & 122 & 90 & 212 & 76 & 198 & 15 & 64 & 186 & 20 \\
\hline & $\mathrm{m}^{3} /$ year & $\mathrm{m}^{3} /$ year & $\mathrm{m}^{3} /$ year & $\mathrm{m}^{3} /$ year & $\mathrm{m}^{3} /$ year & $\mathrm{m}^{3} /$ year & $\mathrm{m}^{3} /$ year & $\mathrm{m}^{3} /$ year & $\mathrm{m}^{3} /$ year \\
\hline & 3844548 & 2843169 & 6687717 & 2385304 & 6229852 & 457865 & 2018304 & 5862852 & 618567 \\
\hline & $57 \%$ SIV & $43 \%$ SIV & $100 \%$ SIV & $84 \% \mathrm{RL}$ & $93 \%$ SIV & $228932 €$ & $71 \% \mathrm{RL}$ & $88 \%$ SIV & $309284 €$ \\
\hline
\end{tabular}




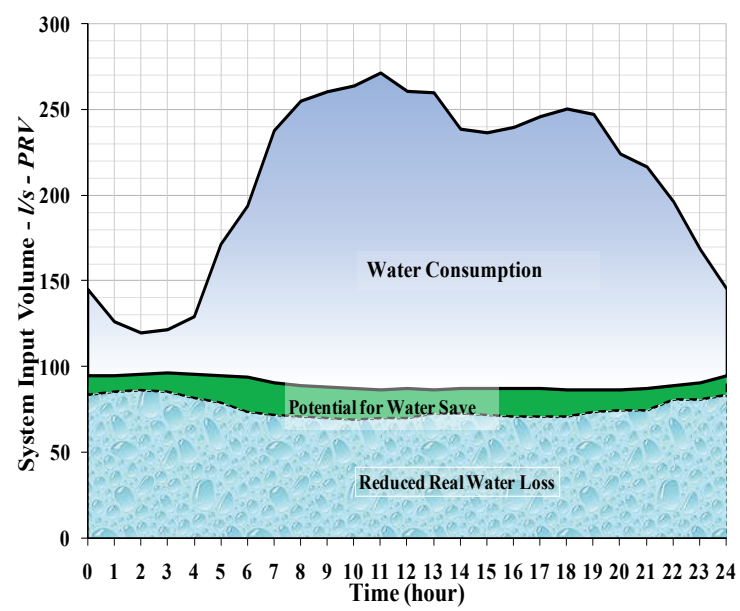

Figure 8 Daily potential for water save after introducing pressure reduction with 10 outlet pressure fixed reduced value (PRV) valves

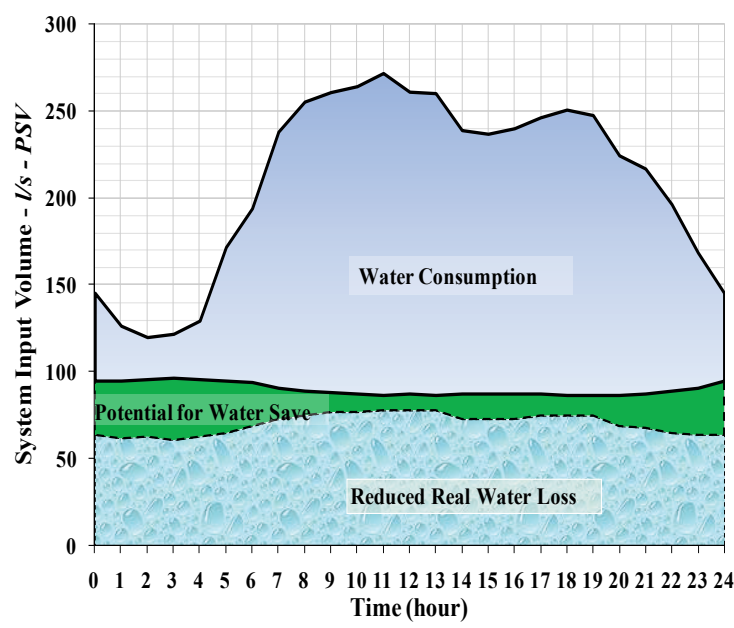

Figure 9 Daily potential for water save after introducing pressure reduction with 10 pressure sustaining value (PSV) valves

All three components of average daily consumption for management scheme with 10 PRV are shown in Fig. 8. $\mathrm{AC}+$ and $\mathrm{RL}$ are separated by the bold line. The dashed line delimits potential water savings from the reduced RL.

In the second case (10 PSV) with simulated reduced pressure control, RL varies between 61 and 78 1/s during a day. Reduction in RL volume estimated by numerical simulations is about $29 \%$ (Tab. 4), and reduction of the total SIV is about $12 \%$. This leakage management scheme has potential to save $618567 \mathrm{~m}^{3}$ of potable water per year, or $309284 €$ for water supply utility (Tab. 4). Three components of Average Daily Consumption for management scheme with 10 PSV are shown in Fig. 9 using the same symbols (lines) to separate its components as in Fig. 8. Water savings come from the reduced RL.

The first pro-active leakage management scheme with $10 \mathrm{PRV}$ is one of the simplest schemes for pressure level maintenance. Fixed outlet pressure, downstream of the PRV has the same value during the whole day. During the night hours, when $\mathrm{AC}+$ has the lowest value, average pressure in the pressure management zone is higher than during the day, so the leakage reduction level is higher during the day than during the night. Consequently, a separate night/day PRV settings scheme has potential to achieve higher WL reduction.

It can be seen from Fig. 9 that 10 PSV provide more active WL management by keeping pressure level fixed in the pressure management zone representative node. In this way, during the night hours, this management scheme keeps pressure at lower level in the pressure management zone compared to the first management scheme.

Calculated RL volume has very low variation during the $24 \mathrm{hrs}$ in all three simulated scenarios - without pressure reduction, and two schemes with pressure reduction. The extreme $\mathrm{RL}$ volume is four times higher than $\mathrm{AC}+$ volume during the night hours (Figs. 8 and 9).

Tab. 5 shows that ILI value remains in the same range despite the PWSS potential to achieve notable water savings and better UARL value by the pressure control. The ILI indicator robustness is therefore verified. Its values point out to poor infrastructural state of the distribution network and a need for the system rehabilitation.

Table 5 Benchmarking Criteria for Real and Simulated System PI Values

\begin{tabular}{|c|c|c|c|}
\hline ITEM & Real & $\begin{array}{c}\text { Simul. } \\
10 \text { PRV }\end{array}$ & $\begin{array}{c}\text { Simul. } \\
10 \text { PSV }\end{array}$ \\
\hline Number of consumers & 46873 & 46873 & 46873 \\
\hline Numb. of reg. serv. conn. & 14412 & 14412 & 14412 \\
\hline Distr. netw. length / km & 120 & 120 & 120 \\
\hline Service conn. length / km & 144 & 144 & 144 \\
\hline Avr. Netw. pressure / m & 45 & 38 & 33 \\
\hline Real Loss Volume / $\mathrm{m}^{3}$ & 2847440 & 2385304 & 2018304 \\
\hline Real Loss of SIV / \% & 43 & 38 & 34 \\
\hline TIRL & 541 & 453 & 384 \\
\hline UARL & 259719 & 219318 & 190460 \\
\hline ILI & 11,0 & 10,9 & 10,6 \\
\hline
\end{tabular}

\section{CONCLUSION}

BPWB and Technical PI recommended by IWA WLTF have proven their usability as objective benchmarking tools in Pirot WSS [12].

A systematic data collection and measurements organized in PWSS targeted to meet IWA WLTF recommendations would lead to better system understanding, action planning and overall long term benefits.

The PWSS has representative infrastructural state for the set of Serbian water supply systems. Real data have been collected on the PWWS performance during the preparatory period. Continuous flow input and recorded tank levels have been used to estimate daily, monthly and yearly consumption and to estimate representative diurnal demand patterns.

PWSS hydraulic model has been calibrated on $\mathrm{AC}+$ (as sum of Authorized Consumption and Apparent Loss) hourly demand patterns and Real Loss parameters, Unit Loss and $N 1$ exponent value. This specific approach created hydraulic model capable of estimating daily variation of the $\mathrm{AC}+$ and Real Loss volume as SIV components.

During the simulation period, calibrated PWSS mathematical model has shown $\mathrm{AC}+$ had significant daily variation (24-185 1/s), while RL had very small daily variation $(87-97 \mathrm{l} / \mathrm{s})$.

It is shown in the paper that there is high leakage level in the PWSS due to current system infrastructural condition. Nevertheless, numerical experiments on modified PWSS network scheme (reshaped in 7 pressure management zones with $10 \mathrm{PRV}$ and $10 \mathrm{PSV}$ ) indicate significant water and financial savings potential. Estimated water saving for the system operation with $10 \mathrm{PRV}$ is 
$457865 \mathrm{~m}^{3} /$ year (about $228932 €$ ). SIV could be reduced by $7 \%$ and volume of RL by $16 \%$. These savings would be higher if night/day PRV operation scheme is applied.

For the simulated system operation with $10 \mathrm{PSV}$, saving is $618567 \mathrm{~m}^{3} /$ year (about $309284 €$ ), SIV could be reduced by $12 \%$ and volume of RL $29 \%$. Therefore, pressure or flow modulation (either time programmed or proactive) has potential for higher water savings in PWSS.

An additional investigation of the PWSS infrastructure state is needed to detect the most prone to leak system parts. This is a starting point for an "Asset Management Plan" for the system systematic rehabilitation. Permanent leakage monitoring [18] in PWSS is strongly recommended, in order to keep control on the system operation and achieve improvement in its performance and effectiveness.

\section{Acknowledgment}

The presented analyses and results are part of the outcomes of the research project "Assessment of Climate Change Impact on Serbia's Water Resources" (TR-37005), 2011 - 2019, of the Ministry of Education, Science and Technological Development of the Republic of Serbia. The authors express their gratitude to the Ministry for its financial assistance and support.

\section{REFERENCES}

[1] Alegre H. (1999). Performance Indicators for Water Supply Systems, Drought Management Planning in Water Supply Systems. Water Science and Technology Library, 32, 148178. https://doi.org/10.1007/978-94-017-1297-2_7

[2] Alegre H. et al. (2000). Losses from Water Supply Systems: Standard Terminology and Performance Measures. IWA Manual of Best Practice.

[3] Alegre H. et al. (2006).Performance Indicators for Water Supply Services, Second Edition. IWA Manuals of Best Practice, 12. https://doi.org/10.2166/9781780405292

[4] AWWA (2009). Water Audits and Loss Control Programs: Manual of Water Supply Practices M36 ( $3^{\text {rd }}$ ed.) Retrieved from: https://www.awwa.org/Portals/0/files/publications/ documents/M36LookInside.pdf

[5] Fantozzi, M. \& Lambert A. (2016, October). Regulation in Water Loss Management and Benchmarking to Achieve Efficiency: an International Perspective IWA Water IDEAS, Intelligent Distribution for Efficient and Affordable Supplies. Bologna, Italy: IWA Publishing

[6] Fontana, N., Giugni, M., \& Marini, G. (2016). Experimental assessment of Pressure-Leakage Relationship in a Water Distribution Network. Water Science and Technology, 17(1). https://doi: 10.2166/ws.2016.171

[7] Karadirek, E., Kara, S., Yilmaz, G., Muhammetoglu, A., \& Muhammetoglu, H. (2012). Implementation of Hydraulic Modelling for Water-Loss Reduction through Pressure Management. Water Resources Management, 26(9), 25552568. https://doi:10.1007/s11269-012-0032-2

[8] Lambert, A. \& Hirner, W. H. (2000). Losses from Water Supply Systems: Standard Terminology and Performance Measures. IWSA Blue Pages.

[9] Lambert A. (2009). Ten Years Experience in Using the UARL Formula to Calculate Infrastructure Leakage Index. IWA Specialist Conference Water Loss 2009. Cape Town, South Africa: IWA Publishing.

[10] Lambert, A., Charalambous, B., Fantozzi, M., Kovač, J. Rizzo, A., \& Galea, St. J. (2014). 14 Years Experience of using IWA Best Practice Water Balance and Water Loss
Performance Indicators in Europe. Retrieved from http://www.mcast.edu.mt/Portals/0/IAS\%20Lib/IWA\%20A pril\%202014-\%20Water\%20Benchmarking.pdf,Accessed 12 March 2018

[11] Pham, D. \& Pu, L. (2014). Optimal Localization of Pressure Reducing Valves in Water Distribution Systems by a Reformulation Approach. Water Resources Management, 28(10), 3057-3074. https://doi.org/10.1007/s11269-014-0655-6

[12] Radivojević, D., Milićević, D., \& Ivetić, M. (2008). Technical Performance Indicators for Water Works, the First Steps in Serbia on IWA Best Practice Application. Performance Assessment of Urban Infrastructure Services Drinking Water, Wastewater and Solid Waste, 207-218.

[13] Radivojević, D. (2013). Technical Performance Indicators for Water Works Benchmarking and Proposed Actions for Technical Upgrading Small Water Works in Serbia, Dissertation, Faculty of Civil Engineering \& Architecture, University of Niš. Retrieved from: https://fedorani.ni.ac.rs/fedora/get/o:774/bdef:Content/get

[14] Siew, C. \& Tanyimboh, T. (2012). Pressure-Dependent EPANET Extension. Water Resources Management, 26(6), 1477-1498. https://doi.org/10.1007/s11269s11269-011-9968-x

[15] Sarbu, I. (2014). Nodal Analysis of Urban Water Distribution Networks. Water Resources Management, 28 (10), 3143-3159. https://doi.org/10.1007/s11269-014-0660-9

[16] Thornton, J. \& Lambert, A. (2005). Progress in Practical Prediction of Pressure: Leakage, Pressure: Burst Frequency and Pressure: Consumption Relationships. Proceedings of IWA Conference 'Leakage Management: A Practical Approach'. Halifax, Canada: IWA Publishing

[17] Tutunović, K. (2004). Water V6.3, Reference manual AquanetS, Engineering Software Solutions, Retrieved from: https://www.scribd.com/document/213509100/Water

[18] Tantsky, F. A. (2012). Water Loss Detectives: Operational Efficiencies from Permanent Leakage Monitoring. Bucarest, Romania: AQUATIM

[19] Water Loss Group (2005). IWA Task ForceBest Practice Performance Indicators for Non-Revenue Water and Water Loss Components: A Practical Approach. Proceedings of IWA Conference 'Leakage Management: A Practical Approach'. Halifax, Canada: IWA Publishing.

[20] Van Zyl, K., Lambert, A. \& Collins, R. (2017). A Theory for Realistic Modelling of Leakage and Intrusion Flows through Leak Openings in Pipes, CCWI 2017. Retrieved from: https://core.ac.uk/download/pdf/84338666.pdf https://doi.org/10.1061/(ASCE)HY.1943-7900.0001346

\section{Contact information}

Dragan RADIVOJEVIĆ, PhD, Teaching Assistant

(Corresponding author)

Građevinsko-arhitektonski fakultet

Aleksandra Medvedeva 14, Niš

E-mail: dragan.radivojevic@gaf.ni.ac.rs

Borislava BLAGOJEVIĆ, PhD, Assistant Professor

Građevinsko-arhitektonski fakultet

Aleksandra Medvedeva 14, Niš

E-mail: borislava.blagojevic@gaf.ni.ac.rs

Aleksandra ILIĆ, Teaching Assistant

Građevinsko-arhitektonski fakultet

Aleksandra Medvedeva 14, Niš

E-mail: aleksandra.ilic@gaf.ni.ac.rs 